\title{
LAS ESCUELAS DE FORMACIÓN DEPORTIVA
}

\section{Mario G. Loaiza*}

Es por todos ya conocido la importancia que posee el juego y toda clase de expresiones lúdicas en la formación de el niño y en general de el hombre. De igual manera sabemos la importancia tan contundente que tiene nuestra etapa infantil, 0-12 años, en la formación de nuestra personalidad, de nuestra manera de desempeñarnos en el futuro; tiene una validez especial aquella sabiduría que dice "Formad al niño para no castigar al hombre». Esta verdad cobra vigencia en nuestros días de una manera relevante al comprobar en nuestra sociedad formas de descomposición tan dramática que nos hacen reflexionar sobre nuestro papel como «mayores» en la estructura del futuro; fenómenos como la perdida de los valores humanos: Honestidad, solidaridad, cooperación, respeto, disciplina, comprensión y cariño entre otros. El incremento de los vicios: alcohol, drogas, juego de azar. Deformaciones de la personalidad: pandillismo, vagancia, prostitución; y una proliferación muy acentuada de problemas de la salud: corazón, sida, estrés, hacen que la sociedad en su conjunto busque alternativas para erradicar estos males que frenen de una u otra manera el desarrollo humano y social.

En el abanico de estas alternativas aparece el deporte, Ley 181 de 1995, como tabla salvadora para «alejar» al joven de la problemática antes descrita. Pero ojo, pero no salgamos de Guatemala para entrar en Guatepior, una práctica deportiva mal implementada puede incurrir en los mismos problemas: egoísmo, apatía, vicios... Ya hemos visto y muy a menudo, como grandes estrellas deportivas dan muestra de "esto» desenfunda su arma de fuego, golpea los periodistas no soportan una rueda de prensa, es un fracaso como cabeza de familia, se dopa y no es capaz de sentir algo de cariño y respeto por el contrario si no que espera la oportunidad de golpearlo, lesionarlo y descargar su odio contra quien hace posible su mismo lucimiento... por eso es muy fácil crear una escuela de formación deportiva pero muy difícil lograr la construcción de hombres con construcción de hombres con extraordinarias condiciones en un deporte especifico, modelos para los que se vienen preparando y dignos representantes de un pueblo, una nación, una Colombia...

\section{BIBLIOGRAFÍA}

MALINOWSKI, Bronislaw. Una teoría científica de la Cultura. Edit. Edhasa. España, 1991.

LAATWEIN. Theo. Sack. Maria. Deporte y occio. Edit. Fontanella, 1995.

MOSSTON, Muska. La enseñanza de la Educación Física. Edit. Paidós. 1992.

ASOCIACIÓN COLOMBIANA DE PROFESORES DE EDUCACIÓN FISICA. XIII Congreso Panamericano de EF. Memorias. Edit. Géminis Colombia, 1991.

\footnotetext{
* Profesor Universidad Pedagógica Nacional. 